Article

\title{
Generalized Framework for the Design of Eco-Industrial Parks: Case Study of End-of-Life Vehicles
}

\author{
Shimaa Al-Quradaghi ${ }^{1,2}$, Qipeng P. Zheng ${ }^{2}$ and Ali Elkamel ${ }^{3, *}$ \\ 1 Department of Mechanical and Industrial Engineering, Qatar University, Doha P.O. Box 2713, Qatar; \\ shaima.ali@qu.edu.qa \\ 2 Department of Industrial Engineering and Management Systems, University of Central Florida, Orlando, \\ FL 32816, USA; qipeng.zheng@ucf.edu \\ 3 Department of Chemical Engineering, University of Waterloo, Waterloo, ON N2L 3G1, Canada \\ * Correspondence: aelkamel@uwaterloo.ca; Tel.: +1-519-888-4567
}

Received: 5 July 2020; Accepted: 11 August 2020; Published: 15 August 2020

\begin{abstract}
Eco-industrial parks (EIPs) are promoting a shift from the traditional linear model to the circular model, where industrial symbiosis plays an important role in encouraging the exchange of materials, energy, and waste. This paper proposes a generalized framework to design eco-industrial parks, and illustrates it with regard to the end-of-life vehicle problem (ELV). An eco-industrial park for end-of-life vehicles (EIP-4-ELVs) creates synergy in the network that leverages waste reduction and efficiently uses resources. The performance of the proposed framework is investigated along with the interactions between nodes. The proposed framework consists of five steps: (1) finding motivation for EIP, (2) identifying all entities with industrial symbiosis, (3) pinpointing the anchor entity, (4) determining industrial symbiosis between at least three entities and two exchange flows, and (5) defining exchange-flow types. The two last steps are connected by a feedback loop to allow future exchange flows. The proposed framework serves as a guideline for decision makers during the first stages of developing EIPs. Furthermore, the framework can be linked to car-design software to predict the recyclability of vehicle components and aid in manufacturing vehicles optimized for recycling.
\end{abstract}

Keywords: eco-industrial park (EIP); end-of-life vehicles (ELVs); industrial symbiosis (IS); design framework; sustainability; process optimization

\section{Introduction}

An industrial ecosystem optimizes the consumption of energy and materials, and minimizes the generation of waste [1]. The study of industrial systems that operate like natural ecosystems is called industrial ecology, in which the natural ecosystem generates waste from one organism to be the resource for another [2]. Similar to the natural ecosystem, the industrial ecosystem capitalizes on the exchanges of one firm's waste to be another firm's resource.

Industrial symbiosis is a subset of industrial ecology and has a particular focus on material and energy exchanges [3]. Eco-industrial parks develop when industrial symbiosis occurs between firms; the interactions include exchanges of material and energy.

Eco-industrial parks (EIPs) promote a shift from the traditional linear model to the circular model. They are considered a community of businesses that reduce the global impact by sharing resources like materials, energy, and water to reduce waste and pollution, and increase economic gains [4]. The interactions in the community improve the environmental performance of the industrial network. EIP is promoting a shift from the traditional linear model of "raw material to industry to 
waste" to a closed-loop model of "raw material to industry A to waste to raw material to industry B". Considering the global strategy, cities are considered at macro level, and single industry at the micro level, and in between, there is the meso level where EIPs exist. EIPs not only exchange waste heat, steam, bio-waste, and industrial waste but also knowledge, material, and energy. The circular process that is built within EIP connects the entities and results in minimum effect on the environment. Hence, solving environmental problems using an EIPs approach is one effective strategy of waste management that limits pollution impacts on the environment. In this way, EIPs can be implemented within industrial districts to encourage eco-design practices and the transition to circular business models that are more sustainable in nature. This will also improve the efficiencies of the existing industrial entities in given districts and thus enables them to improve their competitiveness on a global scale. The first known EIP was in Kalundborg, Denmark; industrial symbiosis gradually evolved over 20 years [5]. Today, many countries have eco-industrial park projects: Argentina, Austria, Brazil, Canada, China, Denmark, Finland, France, Germany, Italy, Netherlands, Norway, Singapore, South Korea, Spain, Sweden, Switzerland, the UK, the USA, and others [3,4,6-11]. Other works vis-a-vis EIPs covered multidisciplinary areas, for example, optimization [12], life-cycle assessments [13], policy implementation [14], social networks [15], and topology [4]. Furthermore, several studies in the literature proposed frameworks for EIPs. For example, on December 2017, the United Nations Industrial Development Organization (UNIDO), joining efforts with German Development Co-Operation (GIZ) and the World Bank Group (WBG), published a document that presents an international framework for eco-industrial parks [16]. The International Framework for Eco-Industrial Parks focuses on four performance categories: park-management, environmental, social, and economic (Figure 1). Each category consists of prerequisites and performance requirements that can be measured. All prerequisites and performance requirements must be met for something to be considered an EIP. The report guides decision makers on the important components to achieve maximal benefits economically, environmentally, and socially. However, as indicated in the report, the International Framework for EIPs provides only strategic details for EIP requirements and does not translate them to existing EIPs.
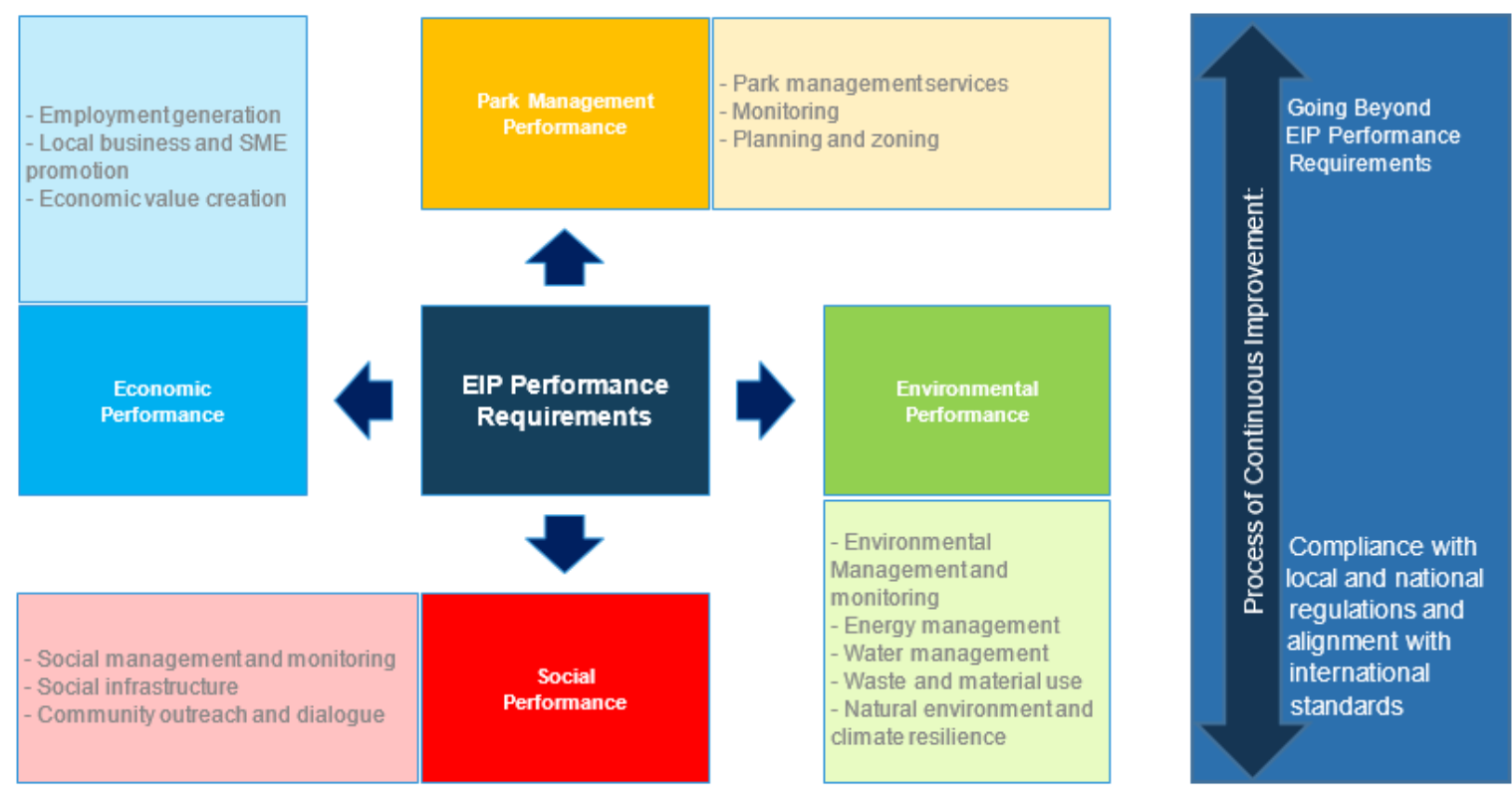

Figure 1. International Framework for Eco-Industrial Parks.

The International Framework for Eco-Industrial Parks created by UNIDO, GIZ, and WBG is not the only initiative to provide essential elements for forming EIPs. Several studies in the literature proposed frameworks for EIPs from different views. There are two common themes for these frameworks, general and special-case. While researchers like [17-25] a general framework for EIPs, other researchers, 
like $[7,26,27]$ proposed more specific frameworks for solving a special-case issue. The reviewed articles are presented in the next sections in chronological order in each theme.

Haskins (2007) proposed a general framework for eco-industrial park development named iFACE. The acronym refers to i-identify stakeholders and their needs; F-frame the problem(s); A-alternatives identification and study the options; $C$-choose and implement a course of action; and E-evaluate continuously. The author expressed the framework as a combination of system engineering, industrial ecology, organizational dynamics, logistics, and supply-chain theories [17].

Sopha et al. (2009) presented a more extended framework for creating industrial-symbiosis modeling. The framework consists of two parts: (1) a system-engineering (SE) process and (2) methods. The SE process consists of six steps: needs identification, defining requirements, specifying performances, analyzing, designing and improving, and implementation. The methods component lists different enabling technologies for each SE process step. Interviewing was proposed for Steps 1-3, brainstorming for Step 1, literature study for Steps 2-6, survey for Steps 2-4, field study for Steps 1-3, and workshop for Steps 3-6. The authors applied the framework on the case of an industrial site in Mongstad, Norway, to increase industrial symbiosis [18].

Boons et al. (2011) proposed a conceptual framework for analyzing the dynamics of industrial symbiosis. The framework has a set of conditions that are referred to as "antecedents" that affects another set of "mechanisms". The mechanisms elaborate on two levels: (1) societal and (2) regional industrial systems. The application of the mechanisms led to outcomes that were reflected on the ecological system and social networks. The authors concluded that the framework helped to build a theoretical understanding of the dynamics of industrial symbiosis [19].

Romero and Ruiz (2013) proposed a nested-system framework for modeling EIP operations. The framework describes the relationship between industrial systems and the environment. The main building blocks for the nested framework are economic, social, and natural systems. In applying the framework, five key properties were taken into consideration: (1) functionality; (2) theoretical knowledge; (3) adaptability; (4) reliability; and (5) life span. The authors supported the framework by merging complex-adaptive-system theory, industrial ecology, and the analysis of existing EIPs [24].

Francois Dumoulin et al. (2016) proposed an environmental-assessment framework for facilitated regional industrial symbiosis. The framework helps to identify all environmental impact in facilitated regional industrial symbiosis. The framework was divided into two main sections: (1) logical basis, where key elements of environment observation are identified; and (2) method, where three steps are performed, namely, identifying environmental impact, designing indicators, and assessing the environment. The authors applied the framework on a case in Réunion, a French territory in the Indian Ocean that had the potential for industrial symbiosis [20].

Kuznetsova et al. (2016) discussed the challenges that eco-industrial parks face and proposed an optimization framework for EIP topology and operation. The framework consisted of two stages, optimization of EIPs' (1) topology and (2) operation. Each stage includes several steps. The framework considers uncertainties in EIP and provides appropriate predictions. The authors detailed uncertainties and risks that should be taken into consideration at the design stage [28].

Andiappan et al. (2016) proposed an optimization-based framework for coalitions in EIP. The framework starts with defining co-operative plants in the intended EIP. Then, the framework continues identifying interactions between plants, uses mathematical models to calculate the symbiosis costs (cost of sharing exchanges between plants), and ends up with the eco-industrial park configuration. The authors used mathematical models for calculating the economic correlations of cost and savings allocation, and performed stability analysis for each entity. The framework was applied to a palm-oil EIP in Malaysia. Results showed an increase in the savings for industries in the EIP [22].

Konstantinova, Johannes, and Vejrum (2019) discussed the importance of trust between stakeholders in industrial-symbiosis initiatives. They developed a conceptual industrial-symbiosis trust framework to facilitate gaining trust between partners. The framework illustrates three notions of trust (ability, integrity, and benevolence) through three trust bases: (1) calculus-, (2) knowledge-, 
and (3) identification-based trusts. In their paper, the authors answered the research question of "How can firms develop trust in the context of industrial symbioses investment?" through proposing the framework that merges industrial symbiosis and management techniques [21].

Tao et al. (2019) proposed a three-dimensional framework for studying the influence of policy on industrial symbiosis from the firm's perspective. The three dimensions are industrial-symbiosis (1) fostering models, (2) implementation stages, and (3) policy instruments. The framework was demonstrated on a horizontal axis that presented ten executive policy instruments, the vertical axis presented five stages of industrial-symbiosis implementation, and the depth axis presented four models of industrial-symbiosis fostering. The authors applied the framework on two existing EIPs, one in the United Kingdom and the other in China [25].

For special case frameworks, Behera et al. (2012) presented the existing Research and Development into Business framework that was developed by the Ulsan EIP Center in South Korea. The framework consists of three main steps: (1) exploring new networks, (2) feasibility study, and (3) commercialization. Each step leads to another step following certain criteria within the framework. The aim of the framework was to design industrial symbiosis between EIP stockholders. As an example, the authors presented the Ulsan industrial symbiosis and explained how it had been developed to reach forty instances of symbiosis, some of which having been designed [7].

Liu and Côté (2017) presented a framework for incorporating ecosystem services into China's EIPs. The framework combines policies, governance, techniques, technologies, key actors, and support organizations to build the industrial symbiosis. In the framework, two main components are the core: Component I, with elements of policies, governance, technologies, and business development; and Component II, with elements of key actors and support organizations. The framework suggested integration between the two components to result in an EIP. The framework was designed to solve China's environmental issues by proposing a circular economy through encouraging eco-industrial park development. The authors suggested that the framework could provide guidance for other EIPs around the world [26].

Gopinath et al. (2018) presented a material-flow framework for the sugar industry on the basis of an extensive literature review. The authors reviewed the literature to find all characteristics of the sugar industry to identify the optimal route that resulted in minimizing waste. The framework details the material flow for the sugar industry and points to several waste types that can be reused by other industries. The paper shows the importance of synergy between different types of sectors [27].

The above sections provided an overview of some available frameworks for EIPs in the literature. The discussions outlined the efforts by scholars with different backgrounds to propose ways and methods for designing EIPs. The review elucidates that although considerable efforts have been done in the literature, essential research regarding applying the approach to different types of systems such as ELVs is still required. Furthermore, the literature revealed the complexity of the available frameworks. In the early stage of designing EIPs, decision makers need a simple, clear, and strategic framework to follow and depend on. After having a solid base about the foundation of the elements in EIPs with a general clear framework, decision makers and the EIP team might follow other comprehensive frameworks that pertain to specific needs, such as optimizing industrial-symbiosis flow, evaluating the firms' trust, proposing policies, and other areas of concern. There exists no generalized framework that compiles precise foundations and simple steps at the same time. Hence, there is a need to investigate and construct a generalized and simple to follow framework for the design of eco-industrial parks. This paper bridges this gap in the literature. A simple and yet comprehensive framework is proposed in this paper. The framework consists of five steps: (1) finding motivation for EIP, (2) identifying all entities with industrial symbiosis, (3) pinpointing the anchor entity, (4) determining industrial symbiosis between at least three entities and two exchange flows, and (5) defining exchange-flow types. Steps (4) and (5) are connected by a feedback loop, which allows any additional exchange flows in the future. The paper illustrates the use of the framework on a special case study that involves end-of-life 
vehicles. Applying the recyclability index proposed by Villalba et al. (2004), the framework can be linked to vehicle-design software to predict the recyclability of different types of components [29].

The remainder of this paper is organized as follows. Section 2 presents the proposed framework for efficiently designing eco-industrial parks. In Section 3, a case study is employed to illustrate the use of the framework. Finally, Section 4 outlines the conclusions and future work.

\section{Generalized Framework for Eco-Industrial Park Design}

With the extensive approaches available in the literature, the need for a straightforward framework is rising. The proposed framework in this section illustrates the foundations of designing eco-industrial parks. It provides general step-by-step actions to be followed in the very early stages of designing EIPs. The framework answers fundamental questions that decision makers need in order to start developing and designing EIPs. In a simple, clear, and step-by-step strategy, the framework lays out necessary actors in the process of designing EIPs. The framework requires primary data that can easily be collected from each entity forming EIPs.

The generalized framework for the design of EIPs consists of five steps (Figure 2): (1) finding motivation for EIP [28], (2) identifying all entities with industrial symbiosis [30], (3) pinpointing the anchor entity [31], (4) determining industrial symbiosis between at least three entities and two exchange flows [4], and (5) defining exchange-flow types [31]. Steps (4) and (5) are connected by a feedback loop to allow additional exchange flows in the future. Used parts should be first put into a used market depending on historical demand. Information on their utilization should be monitored, and a decision to eventually move them to the recycling node and consider them as waste material should be made frequently. This balance between reuse of useful components and recycling them as waste is an important consideration in Step 2 of the proposed methodology.

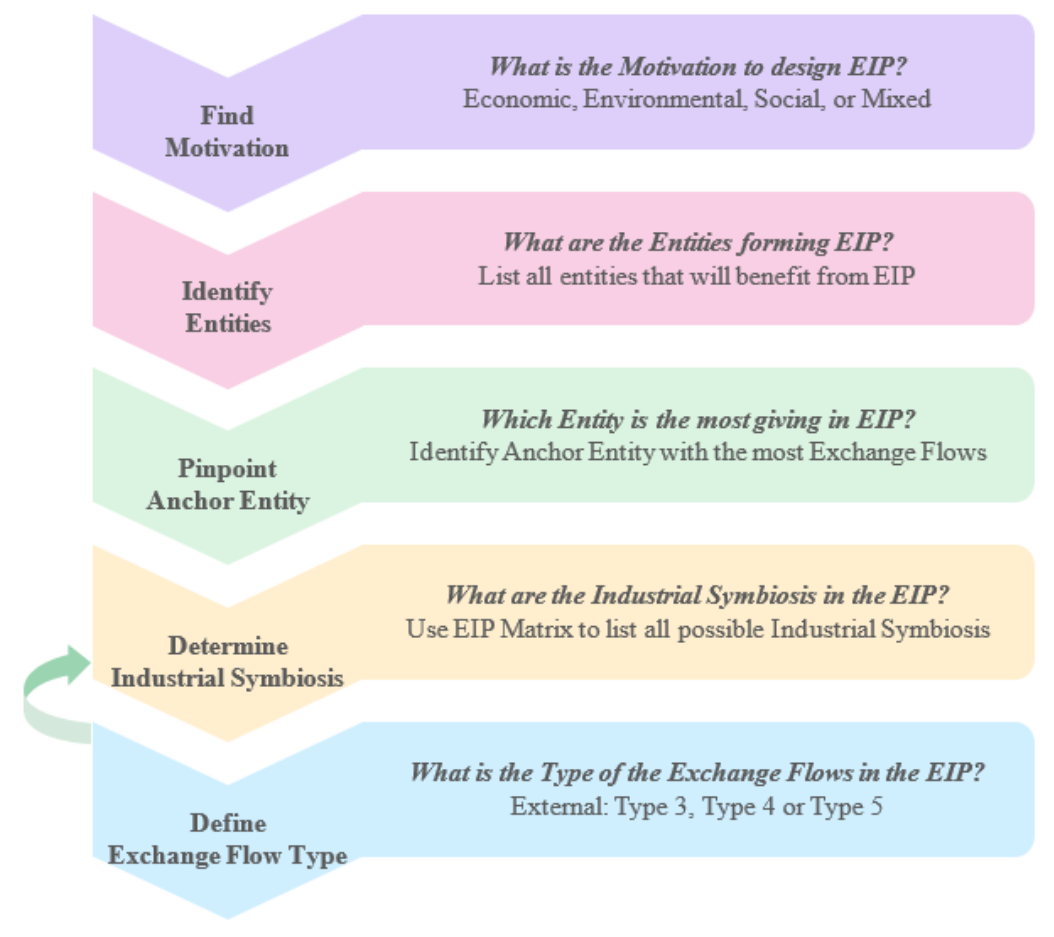

Figure 2. Generalized framework for design of eco-industrial parks.

For creating a successful EIP, a clear motivation should be stated, whether environmental, economic, or mixed [30]. From this point forward, identifying entities shapes the overall components of the network. Next, pointing out the main entity in the network plays a great role in outlining the anchor entity that attracts other entities towards it. 
To ensure industrial symbiosis in the EIP, the 3-2 heuristic rule [4] should be satisfied. This rule states that "at least three different entities must be involved in exchanging at least two different resources" [4]. Hence, it is necessary to generate a full list of possible exchanges in the network [4,32-34]. For this reason, the EIP matrix is proposed to list all industrial symbioses in EIPs (Table 1).

Table 1. Eco-industrial park (EIP) matrix for listing all network exchange flows.

\begin{tabular}{cccc}
\hline Entity 1 & Entity 2 & Entity n \\
\hline Entity 1 & Internal exchange & $\begin{array}{c}\text { Exchange flow(s) } \\
\text { from 1 to 2 }\end{array}$ & $\begin{array}{c}\text { Exchange flow(s) } \\
\text { from 1 to n }\end{array}$ \\
\hline Entity 2 & $\begin{array}{c}\text { Exchange flow(s) } \\
\text { from 2 to 1 }\end{array}$ & Internal exchange & $\begin{array}{c}\text { Exchange flow(s) } \\
\text { from 2 to } \mathrm{n}\end{array}$ \\
\hline Entity n & $\begin{array}{c}\text { Exchange flow (s) } \\
\text { from } \mathrm{n} \text { to 1 }\end{array}$ & $\begin{array}{c}\text { Exchange flow(s) } \\
\text { from } \mathrm{n} \text { to 2 }\end{array}$ & Internal exchange \\
\hline
\end{tabular}

The last step is to identify material-exchange types. Figure 3 illustrates the different exchange types on the basis of the literature. In her study, to find the taxonomy of different material-exchange types, (Chertow, 2000) [30] classified five types: Type 1: Through waste exchanges through third party; Type 2: Within facility, firm, or organization; Type 3: Between firms collocated in a defined eco-industrial park; Type 4: Between local firms that are not collocated; and Type 5: Between virtually organized firms across a broader region $[4,30]$. However, she highlighted that "Types 3-5 offer approaches that can readily be identified as industrial symbiosis" [30]. For that reason, we considered material-exchange Types $3-5$ to be the main types for flows to build EIP. On that basis, we developed Figure 3 to simplify external-exchange Types 3-5.

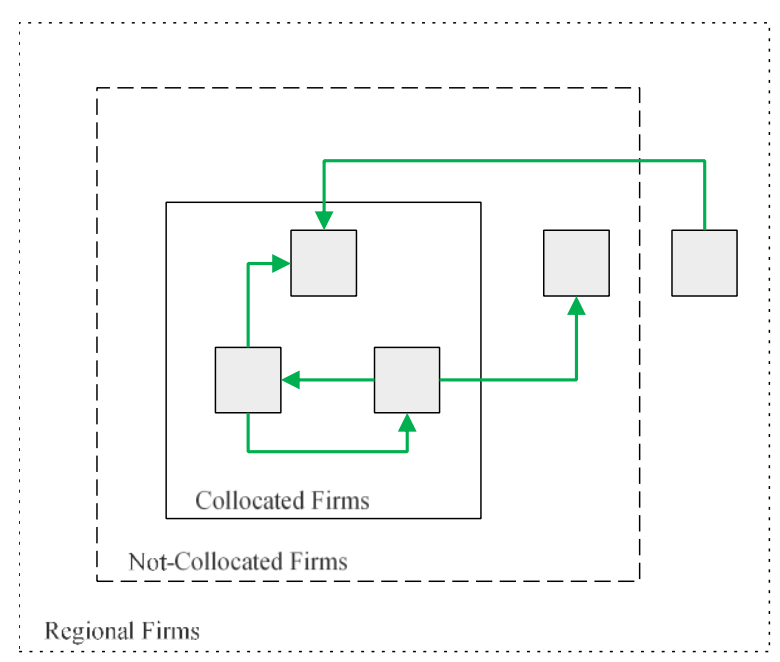

Figure 3. Schematic drawing of different exchange types for industrial symbiosis. Arrows, exchange flows; solid line, collocated-firms boundary; dashed line, non-co-located firm boundary; and dotted line, regional-firm boundary.

The framework has a feedback loop between Steps (4) and (5) that allows for modification and addition whenever there is new industrial symbiosis in the system. The framework results in a connected graph with nodes and arcs. Nodes represent the entities in the network, and arcs represent the exchange flows (Figure 3). The framework steps are elaborated upon in the next subsection.

\subsection{Find Motivation}

This step initially ensures the commitment of creating EIPs. The question, "Why create an EIP?" is very important, and on the basis of the answer, the motivation is clear. The motivation for forming 
EIP can be related to the three pillars of sustainability: economic, environmental, and social. Some companies exchange resources in order to reduce cost or increase profit (economic pillar). Other companies have industrial symbiosis as a way to reduce greenhouse-gas (GHG) emissions and waste (environmental pillar). To go beyond these two reasons, some companies form EIPs to create more job opportunities to people in the EIP region (social pillar). In fact, all these benefits can be met in EIP.

\subsection{Identify Entities}

After knowing the motivation behind forming an EIP, the next step is to identify all possible entities that help in achieving that motivation. Entities in the planned EIP should have exchange flows with other entities from which the EIP benefits.

\subsection{Pinpoint Anchor Entity}

From all entities listed in the previous step, there should be one entity that attracts other entities towards it as it has the most exchange flows to share. The anchor entity is the largest giver in the EIP. It is important to identify the anchor entity to ensure that industrial symbiosis between entities continues.

\subsection{Determining Industrial Symbiosis}

Exchange flows between entities should be listed and determined. This visualizes all possible industrial symbiosis in the EIP. For simplicity, we propose the EIP matrix that lists all industrial symbiosis in the EIP (Table 1). The EIP matrix summarizes all exchange flows and gives detailed information about the network.

\subsection{Define Exchange-Flow Types}

Figure 3 illustrates the different exchange types on the basis of the literature. The types of exchange flow can be defined in this step. In this paper, we considered external-exchange Types $3-5$ as the main flow types to build an EIP. For industrial symbiosis to happen, there needs to be external and not internal exchange flow. We define "internal exchange" as any industrial symbiosis that exists within the entity (e.g., old equipment from one department in the entity can be used in another department). On the other hand, "external exchange" is any industrial symbiosis that appears beyond the boundary of the entity (e.g., old equipment sent to recycling company), including collocated, non-co-located, and regional firms. This requirement is very important, as it identifies the distance between entities and the modes of transportation of the exchange flows (trucks, pipelines, etc.).

\section{Framework Application}

\subsection{ELV Overview}

The European Directive of ELVs 2000/53/EC defines end-of-life vehicles as "vehicles that have become waste", and waste defined as "any substance or object which the holder discards, or intends to discard, or is requires to discard" [35]. According to the Official Journal of the European Communities, end-of-life vehicles account for up to $10 \%$ of the total amount of waste generated annually in the European Union [35]. The directive requires car manufacturers to ensure that a minimum of $95 \%$ by weight per vehicle is reusable and/or recyclable, including a minimum of $85 \%$ of material recoverability (recyclability) or reuse [36].

The waste stream generated from end-of-life vehicles can be controlled/regulated through the vehicle-design phase when product development occurs. "Design for $X$ " is one of several methods to aid the designer in this phase, where " $X$ " refers to the life-cycle phase being evaluated [37-40]. In other words, " $X$ " represents the aim of the design: recycling, quality, sustainability, cost, and so on. It requires the design to meet the specific defined goal $(X)$.

One solution could be introducing design for sustainability (DfS) in the design phase that requires maximizing resource efficiency while minimizing environmental impact $[29,40,41]$. A more specific 
definition for DfS is given by Vezzoli et al. (2018): "A design practice, education, and research that, in one way or another, contributes to sustainable development" [42].

Using recycled scraps benefits the environment threefold by: (i) saving raw materials, (ii) saving energy, and (iii) reducing GHG emissions $[29,41,43]$. Taking steel as an example to demonstrate the use of recycling, every ton of new steel made from scrap steel saves $2500 \mathrm{lb}$ of iron ore, $1400 \mathrm{lb}$ of coal, and $120 \mathrm{lb}$ of limestone (Fold i). The use of recycled scrap steel reduces energy use by $75 \%$ (Fold ii). The estimated GHG reduction for recycling steel in every recycled vehicle is $2205 \mathrm{lb}$ of GHGs (Fold iii; [44]). In general, energy used in recycling scrap materials is less than the energy used in manufacturing raw materials [40,45]. Energy saving and GHG reduction [44] for some metals are illustrated in Figure 4.

(a)

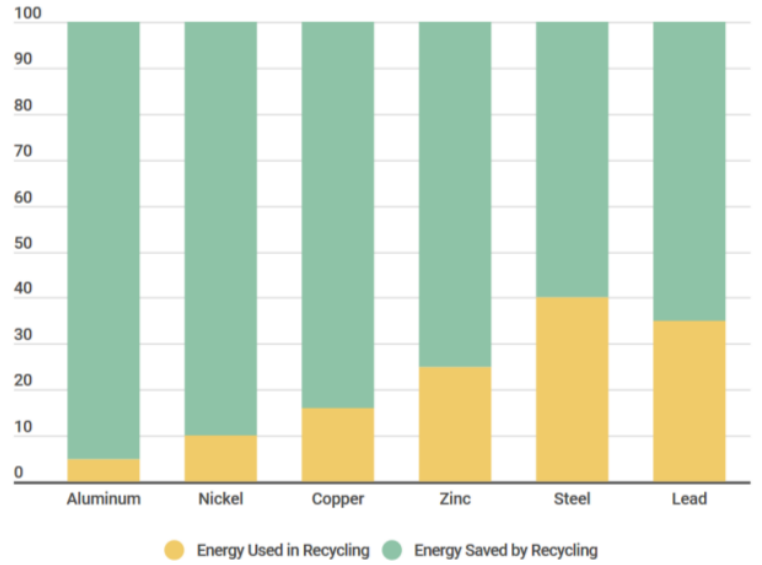

(b)

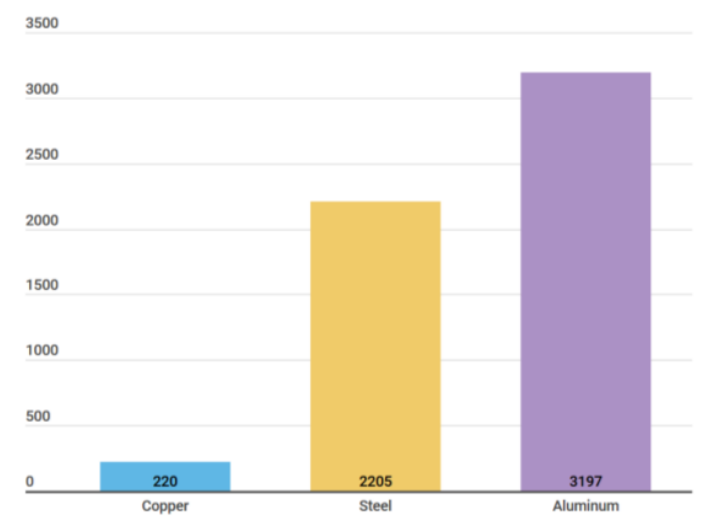

Figure 4. (a) Energy saving for recycling metals; (b) estimated greenhouse-gas (GHG) reduction per recycled end-of-life vehicle (ELV).

However, the dilemma is to figure out if recycling ELVs is economically feasible. Villalba et al. (2002) proposed a recyclability index to measure "the ability of a material to regain its valued properties through recycling process" [45]. The recyclability index calculates the profit-to-loss margin for recycling; hence, it determines whether it is economically feasible to recover the material [29]. With a positive margin, recycling is a good choice; a negative margin indicates some concerns making the material not worth recycling.

The end-of-life-vehicle recycling system aims to isolate hazardous content, and recover usable parts and recycle others [43]. There is a tremendous number of studies in the literature about recycling systems and managing ELVs that were comprehensively studied by $[46,47]$.

Vehicles mainly go through different stages. Maudet et al. (2012) highlighted two main systems for treating ELVs, dismantling components and vehicle shredding [48]. In more detail, Edwards et al. (2006) described three main stages in the recycling process: (1) depollution, (2) dismantling, and (3) shredding [49]. Figure 5 summarizes the overall stages for treating ELVs.
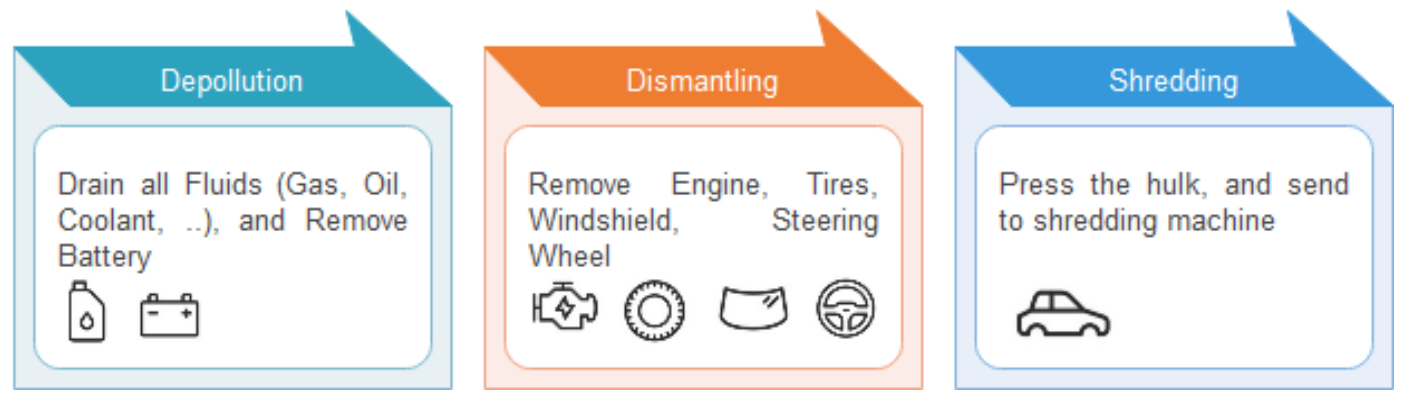

Figure 5. Three main stages in process of treating end-of-life vehicles. 
In the first stage (depollution), all fluids are drained and the battery is removed. The second stage (dismantling) removes the engine, tires, wires, cables, windows, bumpers, and other parts that are useable. In the third stage (shredding), the vehicle's hulk is pressed using a hammermill and then sent to the shredding machine. In the process, ferrous metal is separated using magnetic separation, and an eddy current is used to separate the nonferrous metal. The remainder of that process (plastics, rubber, fabrics, and dirt) is called automobile shredder residue (ASR) or fluff [40,43,49-51]. According to Curlee et al. (1994), ASR generated from recycling ELVs accounts for about $25 \%$ (by weight) of the shredded material [40]. The highest percentage of components in the ASR is fibers, which accounts for $42 \%$ by weight, followed by plastics, with $19.3 \%$ by weight. There are several approaches to separate the components or use the ASR for different purposes [52,53].

ELV management is a crucial issue to deal with for governments, vehicle producers, and treatment facilities. It has received increased attention due to its implications, both economic and environmental. The problem has both tactical and strategic level decision making components. D'Adamo et al. (2020) prepared regression models to predict the amount of ELVs generated yearly as a function of GDP and population. They concluded that given the great amount of ELVs generated, adopting a practical procedure for constructing efficient procedures to connect and induce collaborations between the actors involved in ELV will help greatly in enhancing sustainability and creating economic opportunities [54]. Karagoz et al. provided a comprehensive review of 232 peer-reviewed articles published in the period 2000-2019 that was aimed at identifying the gaps in the ELV management literature [47]. They concluded that only few researchers suggested solutions that closed the waste management loop by recycling and suggested that such approaches should be devised for the solution of real-life ELV management problems to generate reasonable solutions for them. Finally, in a recent article that provided a bibliometric literature review and assessed the efficiency of ELV management, De Almeida and Borsato (2019) concluded that the literature reveals a series of strategies that are confusing [55]. The paper outlined several ELV management strategies and the different processes involved. The paper also concluded that waste management research focusing on the holistic nature of the ELV problem and which considers nodes of different efficiencies is still lacking. Furthermore, the paper suggested future research management strategies that focus on sustainability and the triple bottom line. Therefore, the proposed strategy of the previous section is clearly a step forward towards bridging this gap and its use is illustrated on the case of the ELV management problem in the next sections.

The proposed methodology must also be tailored to the type of vehicles that are in existence in a certain country and also to the specifics of that country. For instance, Che et al. (2011) discuss the specifics of ELV problem in Japan, China, and Korea, and propose different scenarios [56]. For example, labor cost is high in Japan and the design of an EIP (applied to the ELV management problem) must take this into account. This can be done by focusing on automation and taking the economics of the problem into consideration. For example, in the case of several possible alternatives available in one of the suggested nodes by the proposed methodology, the different scenarios must be compared based on a composite objective that considers both the NPV and the sustainability component. In this way, the most desirable alternative with respect to this composite objective is selected. The specific nature of a given country can also be in terms of enforced recycling laws. Step 2 of the methodology that focuses on the identification of all entities with industrial symbiosis must therefore be altered to consider only entities that conform to the law of the country where the recycling unit is to be implemented.

New generation vehicles (NVGs) like hybrid, plug-in hybrid, and electric vehicles are emerging into the market with increasing rates due to advances in battery technology, material design, and computerized technology. These vehicles have different components compared to the traditional fossil fuel vehicles. They are equipped, for example, with highly efficient nickel-hydrogen or lithium-ion batteries. When the proposed methodology is applied to NGVs, in Step 2, which is concerned with the identification of all entities with industrial symbiosis, should take into account the balance between reuse and recycling. For NGVs, there is an emerging trend for the effective utilization of waste batteries [57]. Furthermore, because of the inclusion of these highly efficient batteries, the steel content 
of the vehicles is much lower than that of the traditional fossil fuel vehicles while plastic content is more. For these reasons, non-traditional processing and recycle nodes should be considered for the case of NVGs. Yu et al. (2017) provides a comprehensive analysis of the different recycle and reuse approaches of waste batteries from NGVs [57].

\subsection{Eco-Industrial Park for End-of-Life Vehicles}

The proposed framework was applied to solve end-of-life vehicles (EIP-4-ELVs). The steps of the framework tailored to this case are illustrated in Figure 6. The motivations for the case of EIP-4-ELVs are environmental and economic. End-of-life vehicles are harmful to the environment, so solving this problem is the main motivation. Furthermore, recycling old cars generates profit for many industries. The next step is to identify which industries form the EIP-4-ELVs. The entities are suggested to be power plants, dismantling facilities, waste-to-energy plants, wastewater-treatment plants, glass industries, tire recycling, aluminum, plastic, and steel companies, and battery-recycling or -refurbishing companies. The anchor entity that generates the most waste/byproducts in the case of EIP-4-ELVs is the dismantling facility. This facility is the core of EIP-4-ELVs as it sends out scrap materials of different types to the corresponding industries. Next is to determine all possible exchange flows in the EIP-4-ELVs using the EIP matrix (Table 2). Last is to define the exchange-flow type for transportation purposes-External Type 5 in this case. The feedback loop between the last two steps allows for any future change or modification in the exchange flow. The EIP matrix is provided for this case in Table 2. Cells with (-) indicate possible industrial symbiosis in the future as the EIP evolves.

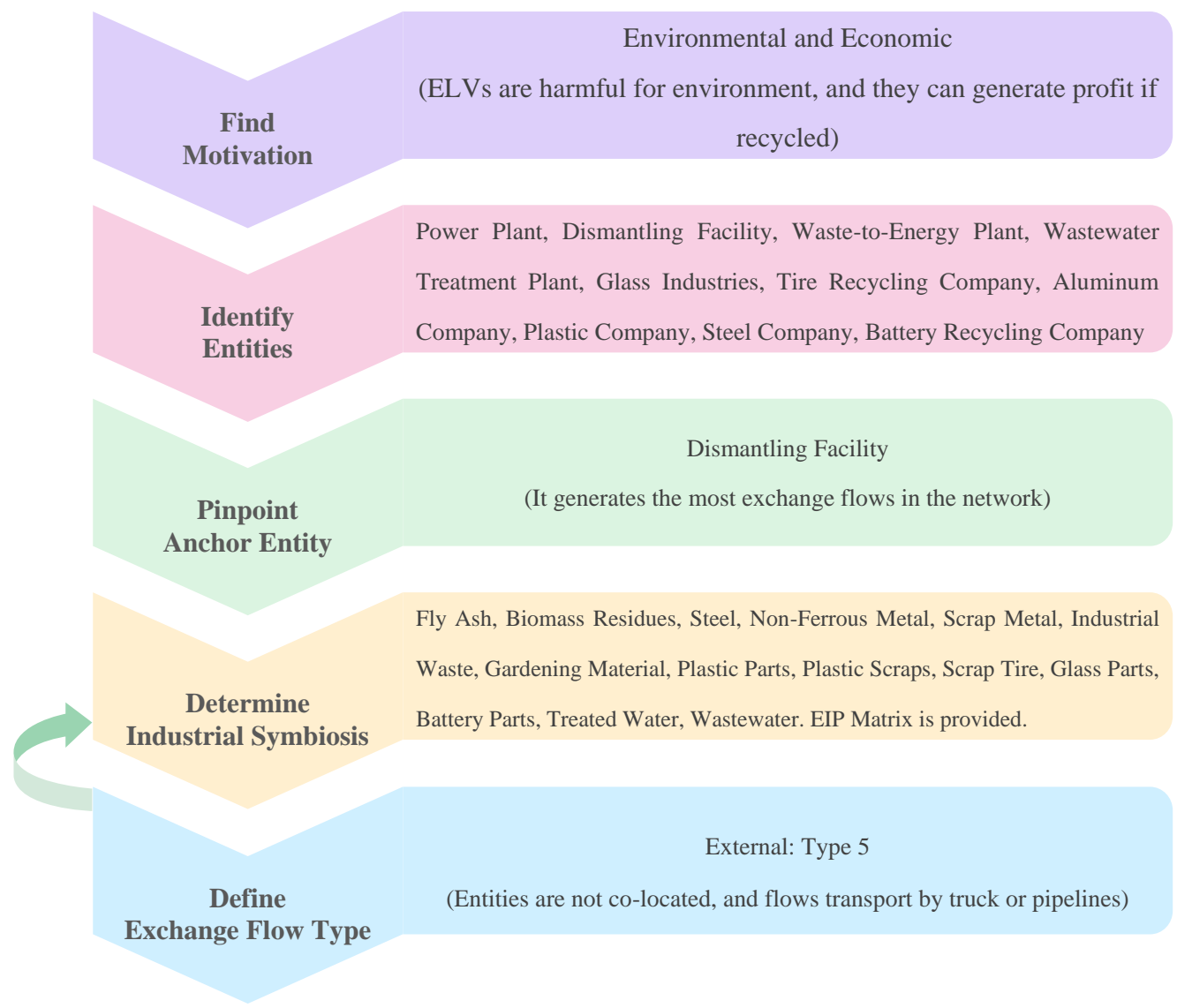

Figure 6. Application of proposed framework to design EIP to solve end-of-life-vehicle problem. 
Table 2. EIP matrix for EIP-4-ELV case.

\begin{tabular}{|c|c|c|c|c|c|c|c|c|c|c|}
\hline & PP & DF & WEP & WTP & GI & TRC & ACo & PCo & SCo & BCo \\
\hline PP & - & Power-to-grid & Power-to-grid & Power-to-grid & Power-to-grid & Power-to-grid & Power-to-grid & Power-to-grid & Power-to-grid & Power-to-grid \\
\hline DF & - & - & Industrial waste & Waste water & Glass parts & Scrap tire & $\begin{array}{c}\text { Nonferrous } \\
\text { metal }\end{array}$ & Plastic parts & Steel parts & Battery parts \\
\hline WEP & Fly ash & - & - & Wastewater & - & - & - & - & - & - \\
\hline WTP & $\begin{array}{c}\text { Treated } \\
\text { water }\end{array}$ & $\begin{array}{l}\text { Treated } \\
\text { water }\end{array}$ & Treated water & - & $\begin{array}{l}\text { Treated } \\
\text { water }\end{array}$ & $\begin{array}{c}\text { Treated } \\
\text { water }\end{array}$ & $\begin{array}{c}\text { Treated } \\
\text { water }\end{array}$ & $\begin{array}{c}\text { Treated } \\
\text { water }\end{array}$ & $\begin{array}{l}\text { Treated } \\
\text { water }\end{array}$ & $\begin{array}{c}\text { Treated } \\
\text { water }\end{array}$ \\
\hline GI & - & - & Industrial waste & Waste water & - & - & - & - & - & - \\
\hline TRC & - & - & - & Waste water & - & - & - & - & Metal parts & - \\
\hline ACo & - & - & - & Waste water & - & - & - & $\begin{array}{l}\text { Plastic } \\
\text { scraps }\end{array}$ & Scrap metal & - \\
\hline PCo & - & - & - & Waste water & - & - & - & - & - & - \\
\hline SCo & - & - & - & Waste water & - & - & - & - & - & - \\
\hline BCo & - & - & - & Waste water & - & - & - & $\begin{array}{l}\text { Plastic } \\
\text { scraps }\end{array}$ & Metal parts & - \\
\hline
\end{tabular}

PP: Power plant; DF: Dismantling facility; WEP: Waste-to-energy plant; WTP: Wastewater-treatment plant; GI: Glass industries; TRC: Tire-recycling company; ACo: Aluminum company; PCo: Plastic company; SCo: Steel company; BCo: Battery-recycling company. 
The anchor entity, as mentioned earlier, is the dismantling facility (DF) that is the main entity for sending byproducts/waste to other industries. The waste and multiple byproducts created from the $\mathrm{DF}$ are considered resources for the other industries. The proposed industrial symbiosis given by the EIP matrix (Table 2) is shown in the connected network of Figure 7. Nodes present industries in the EIP-4-ELVs, and arcs show the exchange flows. The network illustrates how entities in the proposed EIP-4-ELVs can utilize waste from each other.

In the next section, we ran a simulation model to the developed network and present the outcomes. As the aim of this paper was to solve ELVs, the focus was to study the material flows in the proposed system boundary.

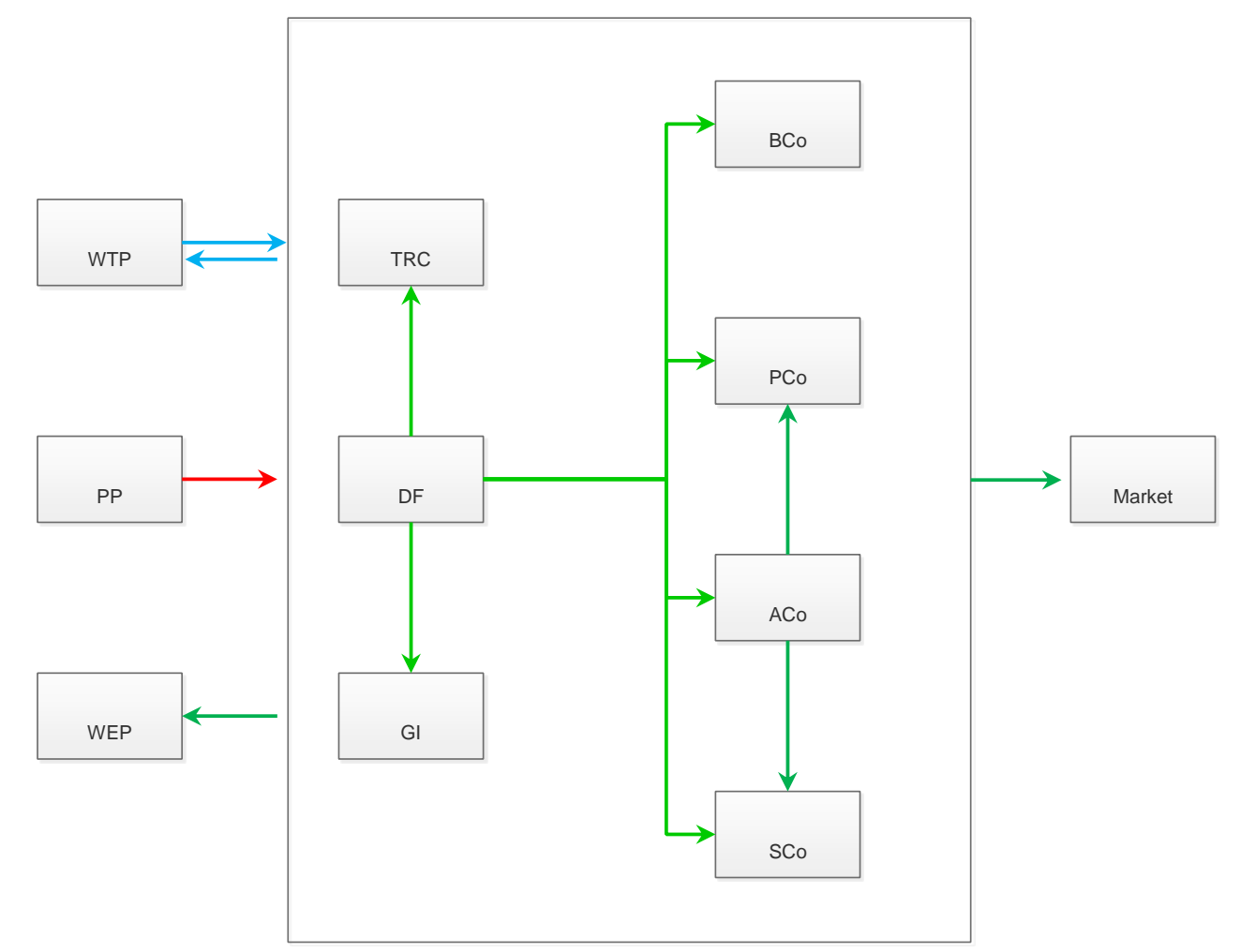

Figure 7. Schematic connected network of exchange flows in EIP-4-ELVs; red, energy flow; blue, water flow; green, material flow.

\subsection{EIP-4-ELV Simulation}

\subsubsection{Model Assumptions}

The vehicle-dismantling facility (DF) is the source for all types of vehicles. In this study, we based our calculations on data given by United Nations Environment Program (UNEP) in the 2013 report titled "Metal Recycling, Opportunities, Limits, Infrastructure" [41], and from the original source, the European Commission Joint Research Center report, "Environmental Improvement of Passenger Cars" (Nemry, Leduc, Mongelli, and Uihlein, 2008). We considered two types of passenger vehicles: petrol and diesel. Table 3 illustrates the composition of an average passenger car from each type, showing the average curb weights for each type. As defined by the U.S. Department of Transportation, curb weight is "the actual weight of the vehicle with a full tank of fuel and other fluids needed for travel, but no occupants or cargo" [58]. 
Table 3. Average material composition of passenger cars (petrol and diesel).

\begin{tabular}{cccccccccc}
\hline & $\begin{array}{c}\text { Total Weight } \\
(\mathbf{k g})\end{array}$ & $\begin{array}{c}\text { Iron and } \\
\text { Steel }\end{array}$ & Aluminum & Glass & Plastic & Tires & Battery & Fluids & Other \\
\hline Petrol & 1240 & 742 & 68 & 40 & 114 & 31 & 14 & 50 & 86 \\
\hline Diesel & 1463 & 959 & 72 & 40 & 114 & 31 & 14 & 50 & 86 \\
\hline $\begin{array}{c}\text { Average weight (Petrol } \\
\text { and Diesel cars) }\end{array}$ & 1352 & 851 & 70 & 40 & 114 & 31 & 14 & 50 & 86 \\
\hline $\begin{array}{c}\text { Percentage of material in average } \\
\text { passenger car: }\end{array}$ & $63 \%$ & $5 \%$ & $3 \%$ & $8 \%$ & $2 \%$ & $1 \%$ & $4 \%$ & $6 \%$ \\
\hline
\end{tabular}

In the available data, this did not add up to the total weight because of the lack of detailed information [58]. For the purpose of this paper, we did the following: (1) added Paint and Textile categories to the other category; (2) calculated the percentage of material; and (3) calculated the average material composition from the two types, and used it instead of weight. The average material composition is shown in Figure 8.

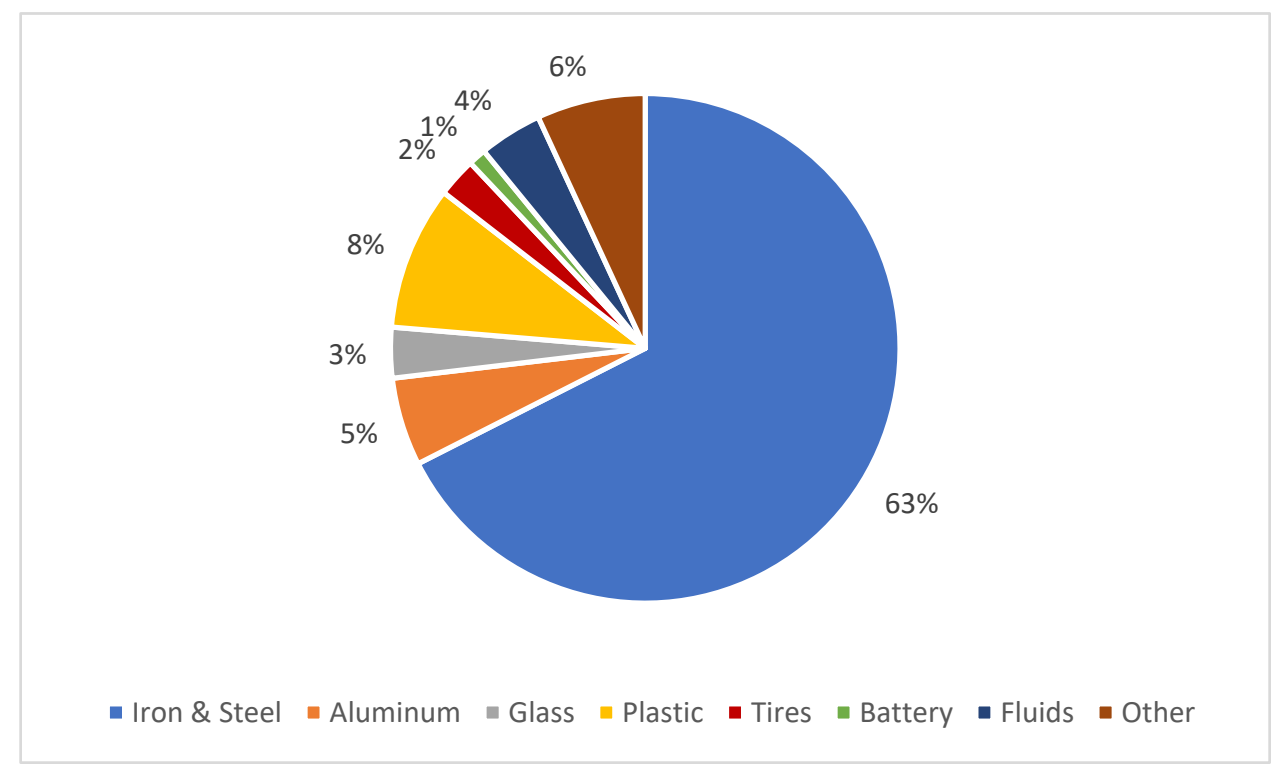

Figure 8. Average material composition in passenger cars (based on petrol and diesel types).

In implementing the model, the following assumptions were made: (1) the dismantling facility operates $10 \mathrm{~h}$ per day (7:00 to 17:00), (2) three Powerhand vehicle-recycling-system (VRS) machines are used to dismantle the vehicles, and (3) average processing time for vehicles is $10 \mathrm{~min}$.

\subsubsection{Model Results}

The connected network of exchange flows (Figure 7) is simulated via the SIMIO software package [59]. The produced results spanning one month ( 28 working days) are shown in Table 4 . As can be seen in the table, the dismantling facility processed 1820 vehicles, and the material outcome from the network could be used for each corresponding industry as a resource. This is only an example of how one month of recycling ELVs produces a different quantity of materials that can be reused. If done for the long term, the EIP-4-ELV network serves in the reduction of raw material extractions and GHG emissions. 
Table 4. Simulation model results for ELVs.

\begin{tabular}{cccccccccc}
\hline \multirow{2}{*}{$\begin{array}{c}\text { Total ELVs Processed } \\
\text { form 28 Working } \\
\text { Days: 1820 }\end{array}$} & Iron and Steel & Aluminum & Glass & Plastic & Tires & Battery & Fluids & Other \\
\cline { 2 - 10 } & 1548 & 127 & 73 & 207 & 56 & 25 & 91 & 157 \\
\hline
\end{tabular}

\section{Conclusions}

Eco-industrial parks (EIPs) promote the shift from the traditional linear to the circular model, where byproducts and waste can be reused. The EIP literature covers multidisciplinary areas, including optimization, life-cycle assessments, policy implementation, social networks, and typology. The International Framework for EIP provided by the UNIDO, GIZ, and WBG report serves as a guide for decision makers on important components to achieve maximal benefits economically, environmentally, and socially. However, as indicated in the report, the International Framework for EIP provides only strategic details for the EIP requirements, and does not translate them into an existing EIP.

On the other hand, the frameworks for EIPs that are provided in the literature are very comprehensive. Hence, there is increasing need for a straightforward framework. The proposed framework illustrates the foundations of designing eco-industrial parks. It shows general step-by-step actions to be discussed at the very early stages of designing EIPs. The framework answers fundamental questions that decision makers need to consider for developing and designing EIPs. In a simple, clear, and step-by-step strategy, the framework lays out necessary actors in the process of designing EIPs. The framework requires primary data that can easily be collected from each entity that forms EIPs.

The proposed framework bridges the gap in the literature and provides a generalized framework for the design of eco-industrial parks. The framework was employed to solve the end-of-life-vehicle problem (EIP-4-ELVs). As a result of applying the framework in EIP-4-ELVs, a connected network of exchanges was built. The outcomes represent the amount of different types of materials. If applied to solve the end-of-life-vehicle problem, the framework can create a connected network that produces different types of materials. By using EIP-4-ELVs, the network prevents using more natural sources, and depends on some percentage of the byproduct exchange from other industries.

Author Contributions: Conceptualization, S.A.-Q., Q.P.Z. and A.E.; methodology, S.A.-Q., Q.P.Z. and A.E.; software, S.A.-Q.; validation, S.A.-Q.; formal analysis, S.A.-Q., Q.P.Z. and A.E.; investigation, S.A.-Q., Q.P.Z. and A.E.; resources, Q.P.Z.; data curation, S.A.-Q.; writing-original draft preparation, S.A.-Q.; writing-review and editing, Q.P.Z. and A.E.; supervision, Q.P.Z. and A.E.; project administration, Q.P.Z.; funding acquisition, S.A. All authors have read and agreed to the published version of the manuscript.

Funding: This research received no external funding.

Conflicts of Interest: The authors declare no conflict of interest.

\section{References}

1. Frosch, R.A.; Gallopoulos, N.E. Strategies for Manufacturing. Sci. Am. 1989, 261, 144-153. [CrossRef]

2. Frosch, R.A. Industrial Ecology: Minimizing the Impact of Industrial Waste. Phys. Today 1994, 47, $63-68$. [CrossRef]

3. Gu, C.; Leveneur, S.; Estel, L.; Yassine, A. Modeling and optimization of material/energy flow exchanges in an eco-industrial park. Energy Procedia 2013, 36, 243-252. [CrossRef]

4. Chertow, M.R. Uncovering' Industrial Symbiosis. J. Ind. Ecol. 2007, 11, 20.

5. Ehrenfeld, J.; Gertler, N. Industrial Ecology in Practice; The Evolution of Interdependence at Kalundborg. J. Ind. Ecol. 1997, 1, 67-79. [CrossRef]

6. Piaszczyk, C. Model Based Systems Engineering with Department of Defense Architectural Framework. Syst. Eng. 2011, 14, 305-326. [CrossRef] 
7. Behera, S.K.; Kim, J.-H.; Lee, S.-Y.; Suh, S.; Park, H.-S. Evolution of 'designed' industrial symbiosis networks in the Ulsan Eco-industrial Park: 'Research and development into business' as the enabling framework. J. Clean. Prod. 2012, 29-30, 103-112. [CrossRef]

8. Tessitore, S.; Daddi, T.; Iraldo, F. Eco-industrial parks development and integrated management challenges: Findings from Italy. Sustainability 2015, 7, 10036-10051. [CrossRef]

9. Mat, N.; Cerceau, J.; Shi, L.; Park, H.S.; Junqua, G.; Lopez-Ferber, M. Socio-ecological transitions toward low-carbon port cities: Trends, changes and adaptation processes in Asia and Europe. J. Clean. Prod. 2016, 114, 362-375. [CrossRef]

10. Aid, G.; Eklund, M.; Anderberg, S.; Baas, L. Expanding roles for the Swedish waste management sector in inter-organizational resource management. Resour. Conserv. Recycl. 2017, 124, 85-97. [CrossRef]

11. Susur, E.; Hidalgo, A.; Chiaroni, D. A strategic niche management perspective on transitions to eco-industrial park development: A systematic review of case studies. Resour. Conserv. Recycl. 2019, 140, 338-359. [CrossRef]

12. Boix, M.; Montastruc, L.; Azzaro-Pantel, C.; Domenech, S. Optimization methods applied to the design of eco-industrial parks: A literature review. J. Clean. Prod. 2015, 87, 303-317. [CrossRef]

13. Zhang, Y.; Duan, S.; Li, J.; Shao, S.; Wang, W.; Zhang, S. Life cycle assessment of industrial symbiosis in Songmudao chemical industrial park, Dalian, China. J. Clean. Prod. 2017, 158, 192-199. [CrossRef]

14. Jiao, W.; Boons, F. Toward a research agenda for policy intervention and facilitation to enhance industrial symbiosis based on a comprehensive literature review. J. Clean. Prod. 2014, 67, 14-25. [CrossRef]

15. Song, X.; Geng, Y.; Dong, H.; Chen, W. Social network analysis on industrial symbiosis: A case of Gujiao eco-industrial park. J. Clean. Prod. 2018, 193, 414-423. [CrossRef]

16. UNIDO; GIZ; WBG. An International Framework for Eco-Industrial Parks; UNIDO: Danver, MA, USA, 2017.

17. Haskins, C. A systems engineering framework for eco-industrial park formation. Syst. Eng. 2007, 10, 83-97. [CrossRef]

18. Sopha, B.M.; Fet, A.M.; Keitsch, M.M.; Haskins, C. Using Systems Engineering to Create a Framework for Evaluating Industrial Symbiosis Options. Syst. Eng. 2009, 13, 149-160.

19. Boons, F.; Spekkink, W.; Mouzakitis, Y. The dynamics of industrial symbiosis: A proposal for a conceptual framework based upon a comprehensive literature review. J. Clean. Prod. 2011, 19, 905-911. [CrossRef]

20. Dumoulin, F.; Wassenaar, T.; Avadi, A.; Paillat, J. A Framework for Accurately Informing Facilitated Regional Industrial Symbioses on Environmental Consequences. J. Ind. Ecol. 2016, 21, 1049-1067. [CrossRef]

21. Konstantinova, Y.; Johannes, E.; Vejrum, B. Dare to make investments in industrial symbiosis? A conceptual framework and research agenda for developing trust. J. Clean. Prod. 2019, 223, 989-997.

22. Andiappan, V.; Tan, R.R.; Ng, D.K.S. An optimization-based negotiation framework for energy systems in an eco-industrial park. J. Clean. Prod. 2016, 129, 496-507. [CrossRef]

23. Yedla, S.; Park, H. Eco-Industrial Networking for Sustainable Development: Review of Issues and Development Strategies. Clean Technol. Environ. Policy 2017, 19, 391-402. [CrossRef]

24. Romero, E.; Ruiz, M.C. Framework for applying a complex adaptive system approach to model the operation of eco-industrial parks. J. Ind. Ecol. 2013, 17, 731-741. [CrossRef]

25. Tao, Y.; Evans, S.; Wen, Z.; Ma, M. The influence of policy on industrial symbiosis from the Firm's perspective: A framework. J. Clean. Prod. 2019, 213, 1172-1187. [CrossRef]

26. Liu, C.; Côté, R. A framework for integrating ecosystem services into China's circular economy: The case of eco-industrial parks. Sustainability 2017, 9, 1510. [CrossRef]

27. Gopinath, A.; Bahurudeen, A.; Appari, S.; Nanthagopalan, P. A circular framework for the valorisation of sugar industry wastes: Review on the industrial symbiosis between sugar, construction and energy industries. J. Clean. Prod. 2018, 203, 89-108. [CrossRef]

28. Kuznetsova, E.; Zio, E.; Farel, R. A methodological framework for Eco-Industrial Park design and optimization. J. Clean. Prod. 2016, 126, 308-324. [CrossRef]

29. Villalba, G.; Segarra, M.; Chimenos, J.M.; Espiell, F. Using the recyclability index of materials as a tool for design for disassembly. Ecol. Econ. 2004, 50, 195-200. [CrossRef]

30. Chertow, M.R. Industrial symbiosis: Literature and taxonomy. Annu. Rev. Energy Environ. 2000, 25, 313-337. [CrossRef]

31. Eilering, J.A.M.; Vermeulen, W.J.V. Eco-industrial parks: Toward industrial symbiosis and utility sharing in practice. Prog. Ind. Ecol. Int. J. 2004, 1, 245. [CrossRef] 
32. Felicio, M.; Amaral, D.; Esposto, K.; Durany, X.G. Industrial symbiosis indicators to manage eco-industrial parks as dynamic systems. J. Clean. Prod. 2016, 118, 54-64. [CrossRef]

33. Heeres, R.R.; Vermeulen, W.J.V.; de Walle, F.B. Eco-industrial park initiatives in the USA and the Netherlands: First lessons. J. Clean. Prod. 2004, 12, 985-995. [CrossRef]

34. Tian, J.; Liu, W.; Lai, B.; Li, X.; Chen, L. Study of the performance of eco-industrial park development in China. J. Clean. Prod. 2014, 64, 486-494. [CrossRef]

35. European Parliament and Council. Directive 2000/53/EC on End-of-Life Vehicles; Official Journal of the European Communities European Parliament and Council: Brussels, Belgium, 2000; L269; pp. 34-42.

36. Garcia, J.; Millet, D.; Tonnelier, P. A tool to evaluate the impacts of an innovation on a product's recyclability rate by adopting a modular approach: Automotive sector application. Int. J. Veh. Des. 2015, 67, 178-204. [CrossRef]

37. Watson, B.; Radcliffe, D. Structuring Design for X Tool Use for Improved Utilization. J. Eng. Des. 2010, 9, 211-223. [CrossRef]

38. Meerkamm, H. Design for X-A Core Area of Design Methodology. J. Eng. Des. 2007, 5, 165-181. [CrossRef]

39. Tonnelier, P.; Millet, D.; Richir, S.; Lecoq, M. Is it possible to evaluate the recovery potential earlier in the design process? Proposal of a qualitative evaluation tool. J. Eng. Des. 2007, 16, 297-309. [CrossRef]

40. Curlee, T.R.; Das, S.; Rizy, C.G.; Schexnayder, S.M. Recent Trends in Automobile Recycling: An Energy and Economic Assessment; Oak Ridge National Laboratory: Oak Ridge, TN, USA, 1994.

41. Reuter, M.A.; Hudson, C.; van Schaik, A.; Heiskanen, K.; Meskers, C.; Hagelüken, C. Metal Recycling: Opportunities, Limits, Infrastructure, a Report of the Working Group on the Global Metal Flows to the International Resource Panel; UNEP: Paris, France, 2013.

42. Vezzoli, C.; Ceschin, F.; Osanjo, L.; M’Rithaa, M.K.; Moalosi, R.; Nakazibwe, V.; Diehl, J.C. Designing Sustainable Energy for All. Sustainable Product-Service System Design Applied to Distributed Renewable Energy; Springer: Cham, Switzerland, 2018; p. 230.

43. Andersson, M. Innovating Recycling of End-of-Life Cars; Chalmers University of Technology: Göteborg, Sweden, 2016.

44. ARA. Automotive Recycling Industry: Environmentally Friendly, Market Driven, and Sustainable; ARA: Manassas, VA, USA, 2012.

45. Graedel, T.E.; Allwood, J.; Birat, J.-P.; Reck, B.K.; Sibley, S.F.; Sonnemann, G.; Buchert, M.; Hagelüken, C. Recycling Rates of Metals-A Status Report, a Report of the Working Group on the Global Metal Flows to the International Resource Panel; UNEP: Paris, France, 2011.

46. Simic, V. End-of-life vehicle recycling-A review of the state-of-the-art. Recikliranje vozila na Kraj. životnog ciklusa-Pregl. Najsuvremnijih Znan. Rad. 2013, 20, 371-380.

47. Karagoz, S.; Aydin, N.; Simic, V. End-of-life vehicle management: A comprehensive review. J. Mater. Cycles Waste Manag. 2019, 22, 416-442. [CrossRef]

48. Maudet, C.; Yannou-Le Bris, G.; Froelich, D. Integrating plastic recycling industries into the automotive supply chain. HAL 2012, 13, 71-89.

49. Edwards, C.; Bhamra, T.; Rahimifard, S. A Design Framework for End-of-Life Vehicle Recovery. In Proceedings of the 13th CIRP International Conference on Life Cycle Engineering, Leuven, Belgium, 31 May-2 June 2006; pp. 365-370.

50. Choi, J.K.; Stuart, J.A.; Ramani, K. Modeling of automotive recycling planning in the United States. Int. J. Automot. Technol. 2005, 6, 413-419.

51. Paul, R. End-of-life management of waste automotive materials and efforts to improve sustainability in North America. WIT Trans. Ecol. Environ. 2009, 120, 853-861.

52. Baker, B.A.; Brookside, N.J.; Woodruff, K.L.; Morrisville, P.; Naporano, J.F.; Fells, N.J.E. Automobile Shredder Residue (ASR) Separation and Recycling System. U.S. Patent WO1995026826A1, 12 October 1995.

53. van Schaik, A.; Reuter, M.A. The optimization of end-of-life vehicle recycling in the European Union. JOM 2004, 56, 39-43. [CrossRef]

54. D'Adamo, I.; Gastaldi, M.; Rosa, P. Recycling of end-of-life vehicles: Assessing trends and performances in Europe. Technol. Forecast. Soc. Chang. 2020, 152, 119887. [CrossRef]

55. de Almeida, S.T.; Borsato, M. Assessing the efficiency of End of Life technology in waste treatment-A bibliometric literature review. Resour. Conserv. Recycl. 2019, 140, 189-208. [CrossRef] 
56. Che, J.; Yu, J.; Kevin, R.S. End-of-life vehicle recycling and international cooperation between Japan, China and Korea: Present and future scenario analysis. J. Environ. Sci. 2011, 23, S162-S166. [CrossRef]

57. Yu, J.; Wang, S.; Toshiki, K.; Serrona, K.R.B.; Fan, G.; Erdenedalai, B. Latest Trends and New Challenges in End-of-life Vehicle Recycling. In Environmental Impacts of Road Vehicles: Past, Present and Future; The Royal Society of Chemistry: London, UK, 2017; Volume 44, pp. 174-213.

58. Kahane, C.J. Vehicle Weight, Fatality Risk and Crash Compatibility of Model Year 1991-99 Passenger Cars and Light Trucks; National Highway Traffic Safety Administration: Springfield, VA, USA, 2003.

59. Joines, J.A.; Roberts, S. Simulation Modeling with SIMIO: A Workbook, 4th ed.; SIMIO LLC: Sewickley, PA, USA, 2015.

(C) 2020 by the authors. Licensee MDPI, Basel, Switzerland. This article is an open access article distributed under the terms and conditions of the Creative Commons Attribution (CC BY) license (http://creativecommons.org/licenses/by/4.0/). 